\title{
Explaining "Memories" of Space Alien Abduction and Past Lives: An Experimental Psychopathology Approach
}

\section{Citation}

McNally, Richard J. 2012. Explaining "memories" of space alien abduction and past lives: An experimental psychopathology approach. Journal of Experimental Psychopathology 3(1): 2-16.

\section{Published Version}

doi:10.5127/jep.017811

\section{Permanent link}

http://nrs.harvard.edu/urn-3:HUL.InstRepos:8862147

\section{Terms of Use}

This article was downloaded from Harvard University's DASH repository, and is made available under the terms and conditions applicable to Open Access Policy Articles, as set forth at http:// nrs.harvard.edu/urn-3:HUL.InstRepos:dash.current.terms-of-use\#OAP

\section{Share Your Story}

The Harvard community has made this article openly available. Please share how this access benefits you. Submit a story.

Accessibility 
Running Head: Alien Abduction and Past Lives

Journal of Experimental Psychopathology (in press)

\author{
Explaining "Memories" of Space Alien Abduction \\ and Past Lives:
}

An Experimental Psychopathology Approach

\author{
Richard J. McNally, Ph.D. \\ Harvard University
}

Journal of Experimental Psychopathology (in press) 


\begin{abstract}
In this article, I describe how my colleagues, students, and I have used the methods of experimental psychopathology to explain why seemingly sincere, nonpsychotic people claim to have memories of being abducted by space aliens or memories from past lives. Our group has used experimental methods from cognitive psychology and psychophysiology, supplementing them with clinical interviews and psychometric tests, to elucidate the psychology of these two groups. Our data point to quasi-spiritual motivations for why some people embrace the identity of alien abductee or past lifer. KEYWORDS: false memory, DRM paradigm, alien abduction, past lives.
\end{abstract}




\section{Explaining "Memories" of Space Alien Abduction and Past Lives:}

\section{An Experimental Psychopathology Approach}

Why do seemingly sincere, nonpsychotic people report memories of space alien abduction or memories from their past lives? Curious about such matters, my research group has investigated this issue by applying the methods of experimental psychopathology. The purpose of this article is to provide an account of how we wound up studying such strange topics in the laboratory, and to summarize what we have learned about these two "false memory syndromes."

\section{Origins in the "Memory Wars"}

My colleagues, students, and I had conducted experimental psychopathology studies on war veterans with posttraumatic stress disorder (PTSD) for many years (e.g., McNally et al., 1987). However, one of my Ph.D. students, Lisa Shin, was keen to broaden our scope from men whose PTSD arose from combat (Shin et al., 1997) to women whose PTSD arose from childhood sexual abuse (CSA). Specializing in neuroimaging, Lisa was interested in studying the functional neuroanatomy of traumatic recollection (Shin et al., 1999). As one of the clinicians on this project, I interviewed 
potential participants to identify those with and without PTSD. During the course of about ten days, I assessed three women who responded to our advertisement but who said that they had no memories of abuse. I first thought that they misunderstood the ad, but that was not the case. I then asked them as politely as possible, "How is it that you responded to our ad, yet you do not recall any abuse?" In reply, they mentioned that they had been experiencing a diversity of seemingly inexplicable symptoms such as nightmares, feeling uncomfortable around a certain relative, mood swings, and sexual difficulties. They concluded that their problems must have arisen from repressed memories of childhood sexual abuse. Lacking autobiographical memories of abuse, they could not participate in the neuroimaging study. These interviews sparked my interest in conducting laboratory studies of people who report repressed memories of CSA.

The "Memory Wars" (Crews, 1995) were raging at the time, especially in the Boston area where many of the "combatants" lived. Yet cognitive experimental psychology research was nonexistent on people reporting repressed and recovered memories of CSA, as far as I knew. Accordingly, I mentioned the three repressed-memory cases to my cognitive psychology colleague, Daniel Schacter. I suggested that we recruit such 
participants from the community and study them in the lab. Dan was keen to collaborate, although he wondered whether we might find enough of them. He thought that the string of cases I had interviewed might have been a fluke.

As it turned out, we found no shortage of participants. My Ph.D. student, Susan Clancy, and my colleague from Harvard Medical School, psychiatrist Roger Pitman, joined Dan and me as we launched our first series of studies. Our group initiated experiments testing hypotheses about mechanisms that ought to be operative if people can either inhibit recollection of memories of CSA or form false memories of CSA (For reviews, see McNally, 2003, pp. 260-274; McNally, in press) .

In one of our studies, we found that women who reported recovered memories of CSA exhibited a heightened propensity for false memories on a laboratory task relative to women who reported never having forgotten their abuse (Clancy, Schacter, McNally, \& Pitman, 2000). On the one hand, this experiment was consistent with the possibility that recovered memory participants might be prone to form false memories outside of the laboratory, including memories of abuse. Yet such a bold inferential leap was unwarranted. Indeed, we had no idea how many (if any) of these participants had false 
memories, nor how many had recalled genuine abuse episodes that had not come to mind for many years. As we later learned (Clancy \& McNally, 2005/2006), one need not appeal to the empirically indefensible notion of repression of traumatic memories (McNally, 2004, 2007; Piper, Pope, \& Borowiecki, 2000) to realize that normal forgetting processes can explain why some abuse victims do not think about their abuse for many years, only to recollect it later.

How I Became a Space Alien Abductee Researcher

Susan and I had originally considered recruiting participants who reported satanic ritual abuse as a means to study false memory propensity in participants whose memories were almost certainly false. However, we soon changed course after I received an invitation to participate in a weekend conference at Harvard Divinity School on "anomalous experiences" that John Mack, an eminent, Pulitzer-prize winning psychiatrist at Harvard Medical School was hosting. I was among about two dozen scholars he had invited. The conference was not open to the public, and the media were not notified.

Several years prior to the conference, John had gotten into a dust-up with our medical school after he published his bestselling book, Abduction: Human Encounters with Aliens 
(Mack, 1994). Worried that he was inadvertently fostering false memories of alien abduction during hypnotic sessions with his research participants, the medical school launched an inquiry into his work. News of the inquiry somehow leaked to the press, and the media had great fun at Harvard's expense. One headline in The Boston Herald read, "E.T., Phone Harvard."

The inquiry panel urged him to abandon hypnotic memory recovery sessions and to solicit input from other scholars. In response, John obtained a grant from the Fetzer Foundation to host a conference on "anomalous experiences" -- his code word for alien abduction.

When I arrived at the conference, I was surprised at the diversity of disciplines represented. By my lights, the "problem of alien abduction" fell squarely in the domain of psychology (or psychiatry). Yet representatives from astronomy and physics were present, as well as a Greek Orthodox priest, a historian of science, an anthropologist who studied mystical experiences, and a psychologist who studied communication among different species of nonhuman primate. This psychologist wryly guessed that John must have invited him as someone who could illuminate how space aliens manage to communicate with their human abductees. (One of my 
abductee participants later told me the answer: "by telepathy")

A panel of several "experiencers" (i.e., space alien abductees) participated, telling their remarkable abduction stories, including tales of being whisked through bedroom walls and up into spaceships for hybrid breeding, and other medical procedures. They were bright, articulate, pleasant, and seemingly sane. Because the nominal aim of the conference was to stimulate research on anomalous experiences, I announced that I was interested in testing whether "experiencers" would exhibit the psychophysiologic signature of PTSD in the laboratory when recalling their most terrifying alien encounters. The abductees were open to the idea, and the following week I told Susan that we should forget about "satanic ritual abuse victims" and study space alien abductees instead. The positive reception I got from the experiencers convinced me that it was the way to go. Susan and I then secured funding to support experimental research on abductees.

Prior to the conference, John had asked me to give a talk at PEER (Program for Extraordinary Experience Research), his research center a few blocks away from my office in the Department of Psychology. I spoke about our memory research 
on CSA victims, and I expressed my interest in moving into the alien abductee business. He asked me how I would recruit my participants, and I told him that I would place an advertisement in the newspaper. He warned me that I would be unlikely to identify real experiencers this way. I warily asked him what he meant by "real" ones. He replied that I would wind up having pranksters contacting my lab.

He was right. After we ran our advertisement in the Boston Globe, that asked readers, "Have you been abducted by aliens?", we had a flurry of messages on our answering machine in the lab. One man left a message nearly every night for about two weeks, consisting of him making strange noises ("Eeek, onk, blip, bleep") amounting to his rendition of an extraterrestial language. Another caller calmly stated his name ("Bob Smith," my pseudonym for him), said that he was an abductee, and that he wanted to learn more about the research, as he was interested in participating. He sold cars at a Boston dealership, and he asked us to phone him at work. When Susan phoned him, explaining that she was responding to his phone message expressing interest in participating in our research on alien abductees, he replied, "What?! Alien abduction?!" Susan heard his fellow sales 
representatives laughing uproariously on the other end of the line as the real "Bob Smith" slammed down the phone. Despite such inauspicious beginnings, we did manage to recruit enough "real" abductees to complete our research. That is, my colleagues and I were convinced of the sincerity of our participants, and confident that no pranksters would up in our study. Although we paid participants a modest honorarium, involvement in our research required multiple sessions involving detailed abduction interviews, completion of questionnaires, laboratory memory tests, psychiatric interviews, and psychophysiological assessment after having provided detailed narratives of neutral, positive, stressful, and abduction memories (see below). The sheer time and effort ensured that only motivated and (presumably) sincere abductees enrolled in protocols.

However, one person did enroll in our past life research who soon admitted that she was not a "real" past lifer. Apparently stressed (or bored) with attempting to maintain her pretense during the detailed initial interview, she confessed to faking it.

\section{Our Studies on Space Alien Abductees}

Our first abductee publication directly arose from our previous study on CSA participants (Clancy et al., 2000). We 
recruited three groups (Clancy, McNally, Schacter, Lenzenweger, \& Pitman, 2002). One group comprised adults who reported "memories" of extraterrestial kidnapping, whereas a second group reported a history of alien abduction, but had no autobiographical memories of the experience. These participants inferred abduction from diverse indicators such as mysterious marks on their bodies, panic attacks triggered by seeing pictures of the movie character E.T., and an inexplicable passion for reading science fiction. When Susan asked them what happened to their memories, they conjectured that the aliens had zapped the memories from their brains or that the abduction had occurred in "another dimension." The third (comparison) group comprised participants who denied ever having been kidnapped by space aliens.

As we did in our study of CSA (Clancy et al., 2000), we used a variant of the Deese/Roediger/McDermott (DRM) paradigm to test for false memory propensity in our abductees (Deese, 1959; Roediger \& McDermott, 1995). We asked participants to listen to a series of lists containing 15 words. Each list converged on a theme represented by a critical lure word that participants never heard. For example, the list might contain words such as sugar and candy with a critical lure of sweet. When we asked participants to recall all words from a 
list, we tested whether they would falsely recall hearing the critical lure word. At the end of the experiment, we also had them read a list of words containing ones that they had heard, distracter words that never occurred, plus the critical lures. We asked them to circle all words that they recognized as having heard.

Consistent with our hypothesis, we found that both abductee groups had rates of false recall and false recognition about twice the rate as the comparison group of participants who denied experiencing alien abduction. The strongest predictor of false recall was the score on Tellegen and Atkinson's (1974) absorption questionnaire -- a measure related to a vivid imagination and a rich fantasy life. of our participants who reported actual "memories" of abduction, most also participated in our script-driven imagery study on the psychophysiology of abduction memories (McNally et al., 2004). In this experiment, we tested whether abductees exhibit the psychophysiological signature characteristic of PTSD patients who hear audiotaped accounts of their traumatic experiences in the laboratory (Orr, Metzger, \& Pitman, 2002). Following procedures devised by Peter Lang's group (Lang, Levin, Miller \& Kozak, 1983) and adapted by my colleagues Roger Pitman and psychophysiologist, 
Scott Orr, we first asked 10 abductees to provide written accounts of their two most terrifying encounters with space aliens. We also asked them to provide written descriptions of their most stressful experience unrelated to abduction (e.g., an accident), their most positive experience (e.g., birth of a child), and a neutral experience (e.g., mowing the lawn). For each of these five scripts, we had them read a list of physiological reactions (e.g., sweating, pounding heart) that they recalled experiencing during the events described in the narratives. I then wrote 30-sec narratives in the second person, present tense that captured the essence of each of the events. Scott Orr audiotaped each narrative in a neutral voice, ensuring that each lasted 30 seconds. It occasionally took scott several tries to record these narratives properly. He would sometimes burst out laughing while trying to record these stories with the necessary solemnity.

Here is a typical alien encounter narrative based on a hypnotically recovered "memory":

You are on the ship, walking down a corridor with an alien. You enter a room and see a group of hybrid children playing. They are half alien, and half human. Walking into another room, you see a group of aliens and 
humans standing in a circle around a table. Suddenly you realize that you must make love to this alien woman right there in front of everyone. Your heart begins to beat faster and your hands become clammy and sweaty. Your face is flushed and you feel warm. You hate this. You detest having sex with this slimy, nonhuman alien. But you have no choice. You are lying naked on the table and she mounts you. You feel sick to your stomach.

Our comparison group comprised 12 individuals (seven women) who denied a personal history of space alien abduction. We "yoked" each of them to an abductee so that they heard the audiotaped neutral, positive, stressful, and abduction scripts of a stranger. We thereby controlled for the possibility that anyone listening to these wild stories of extraterrestial encounters might react psychophysiologically to them.

We conducted focused contrast analyses, testing the hypothesis that abductees would exhibit greater reactivity to traumatic scripts (abduction and stressful) than to nontraumatic scripts (positive and neutral), relative to the comparison group. The data confirmed this hypothesis for all three measures of physiological reactivity: heart rate, skin 
conductance, and electromyographic activity in the left lateral frontalis muscle, signifying facial muscle tension. Hence, prompted by their audiotaped scripts, recollection of alien encounter memories produced reactions statistically indistinguishable from recollection of extremely stressful memories. In fact, reactivity to the abduction scripts was at least as great as the reactivity of Vietnam veterans with chronic PTSD when they listened to scripts of their warrelated traumatic events (Keane et al., 1998). Our control participants exhibited very little psychophysiologic reactivity while listening to the abduction (or stressful) scripts. After completing the experiment, some of them shrugged and said, "Hmmmm, that was weird."

Natasha Lasko did the psychiatric interviews for both groups of participants. Across the 10 abductees, she diagnosed one each of the following disorders: panic disorder, anxiety disorder due to alcohol dependence, specific phobia of insects, bipolar disorder Nos (not otherwise specified), and subthreshold PTSD. As for past disorders, she diagnosed two cases of major depression, one case of alcohol abuse, one case of cannabis dependence, and three cases of subthreshold PTSD. Each case of subclinical PTSD was associated with recovered memories of alien 
abduction. Among the comparison participants, she diagnosed no current disorders and one case of past major depression. Psychometric data also confirmed the mental health of the abductees. For example, their mean score on the Beck Depression Inventory II (Beck \& Steer, 1987) was 3.6 and their mean score on the Trait Anxiety Inventory (Spielberger, Gorsuch, Lushene, Vagg, \& Jacobs, 1983) was 36.1. In contrast to these measures, the abductees scored significantly (ps < .039 - .001) higher than comparison participants did on the Dissociative Experiences Scale (Bernstein \& Putnam, 1986; 8.4 versus 3.3), Magical Ideation (Eckblad \& Chapman, 1983; 9.2 versus 2.9), and absorption (Tellegen \& Atkinson, 1974; 21.6 versus 9.6). In other words, the abductees were neither depressed nor anxious, but they had reported unusual alterations in consciousness, belief in unconventional modes of causation, and had vivid imaginations and a rich fantasy life.

A Recipe for a Space Alien Abductee

In addition to our laboratory and psychometric work, Susan Clancy and I did in-depth interviews with the abductees. She later expanded this material into a book (Clancy, 2005). Taken together, our findings suggest the 
ingredients for a recipe for a space alien abductee. The more of these elements that are present, the more likely someone will have "memories" of alien abduction.

First, anyone who entertains the possibility that aliens are routinely whisking earthlings up to spaceships, probing them medically, and extracting their ova and sperm for hybrid breeding tends to have unusual ideas. Indeed, our abductees score high on a measure of magical ideation, and most endorse New Age-like ideas such as belief in foretelling the future/tarot cards (70\%), astrology (60\%), ghosts (70\%), and bioenergetic healing therapies (70\%), and alternative/herbal remedies (80\%). By contrast, endorsement rates for these ideas in our comparison group were: belief in foretelling the future/tarot cards (8\%), astrology (25\%), ghosts (42\%), and bioenergetic healing therapies (17\%), and alternative/herbal remedies $(58 \%)$.

Second, when I asked our participants how their encounters with aliens began, they described what appear to have been episodes of isolated sleep paralysis accompanied by hypnopompic ("upon awakening") hallucinations (Hufford, 1982; McNally \& Clancy, 2005a). Participants mentioned awakening shortly before dawn, attempting to roll over in bed, and suddenly noticing a complete inability to move. Terrified by 
their sudden paralysis, they soon began to feel electricity coursing through their bodies, to see flashing lights, to hear buzzing sounds, and to glimpse the presence of alien intruders in the semi-darkness of their bedrooms. Some experienced the sensation of levitating off the bed. Our participants spontaneously mentioned these experiences when recounting their history of alien encounters.

Episodes of isolated sleep paralysis are nonpathological "hiccups" in the architecture of rapid eye movement (REM) sleep, the stage of sleep when we do most of our dreaming (Hobson, 1995). During REM, we experience full body paralysis (except for our eyes), and hence are incapable of acting out our dreams and becoming injured. Yet many individuals occasionally undergo desynchrony in the architecture of REM whereby they emerge from dreaming while motor paralysis remains in effect. The hallucinations they experience are the intrusions of lingering REM imagery into emerging wakefulness. Most episodes subside within a minute or so. Because most people are unaware of the mechanisms mediating the phenomenon, they experience terror. Although some assume that they must have been dreaming, despite being awake during the episode, others interpret hallucinated figures as ghosts, angels, and demons as well as space aliens 
(Hinton, Pich, Chhean, Pollack, \& McNally, 2005; Hufford, 1982; McNally \& Clancy, 2005b). Although we did not study our participants in a sleep laboratory, their descriptions of their initial alien encounters fit the description of isolated sleep paralysis accompanied by hypnopompic hallucinations. Indeed, sleep paralysis episodes are difficult to capture in the laboratory because they are infrequent and unpredictable.

Third, after experiencing sleep paralysis episodes, 80\% of our abductees underwent hypnotic memory recovery sessions whereby mental health professionals specializing in alien abduction helped them "recall" what occurred after they awoke in a paralyzed state. Often using leading questions, they stimulated the vivid imaginations of our participants, "helping" them "recall" blocked memories of hybrid breeding, medical probing on spaceships, and so forth. At least among our participants, vivid "memories" of alien encounters came after sleep paralysis episodes.

Fourth, elevated scores on absorption, a trait related to fantasy proneness, vivid imagery, and hypnotizability are common among abductees (MCNally et al., 2004). We suspect that people high on this trait are especially likely to 
recover vivid "memories" of alien encounters during hypnotic sessions.

Fifth, familiarity with the cultural narrative of alien abduction is also important. Images of the typical alien are ubiquitous in American culture as are those of Santa Claus, and it is little wonder that abductees throughout the country report broadly similar kinds of alien encounters. As Clancy (2005, pp. 87-105) has documented, alien contact narratives have closely tracked the appearance of the aliens and their spaceships as Hollywood has depicted them throughout the years. Bestselling books have provided further details of what it is like to be kidnapped by space aliens (e.g., Mack, $1994)$.

In summary, the ingredients for a space alien abductee include: 1) New Age beliefs (e.g., high scores on measures of magical ideation), 2) episodes of isolated sleep paralysis accompanied by hypnopompic hallucinations, 3) hypnotic memory recovery sessions, 4) high scores on a measure of absorption, and 5) familiarity with the cultural narrative of alien abduction. We cannot say whether any of these ingredients is essential or whether our recipe applies to abductees who have never been in our research program. 
Our research on the alien abduction phenomenon incited a media storm that lasted for years. Susan Clancy, Scott Orr, and I made numerous appearances on television and radio, explaining how our findings show how sincere, nonpsychotic people could come to believe that they were victims of extraterrestial kidnappings. Print journalists published excellent stories on our work, including one entitled "Cracking the Harvard X-Files" that appeared in Psychology Today and subsequently reprinted in the annual volume Best Science Writing (Perina, 2004). Hence, we had the opportunity to educate the public, providing a scientific account of a phenomenon of perennial interest.

However, the members of the international space alien abductee community were not amused by our terrestrial explanation for their anomalous experiences. The Internet afforded the opportunity for angry believers in alien abduction to trash us as close-minded skeptics. One common criticism was that we presupposed that reports of abduction were incorrect. Our critics argued that true scientists would entertain the possibility that alien abductions occur.

This criticism misses the mark. There are two common explanations for why sincere, nonpsychotic people report recollections of alien abduction. One explanation is that 
they were abducted by aliens. The second explanation comprises the ingredients in the recipe I describe above (e.g., sleep paralysis, absorption). In principle, either hypothesis could be true. However, the first one is inconsistent with an immense amount of solid science in the fields of astronomy, physics, and biology, whereas the second one is not. An abductive inference -- or inference to the best explanation (Harman, 1965) -- leads one to accept the hypothesis as likely true that best accounts for a phenomenon without clashing with relevant, well-established findings. In other words, one would have to reject a tremendous amount of science to accept the hypothesis that extraterrestrial kidnappings explain reports of alien abduction. In contrast, our explanation does not require us to reject the findings of astronomy, physics, and biology.

\section{From Space Aliens to Past Lifers}

A new Ph.D. student, Cynthia Adelle ("C. A.")

Meyersburg, was keen to pursue issues of false memory further, and she hit upon the idea of investigating people who report memories from past lives. I ran across a notice for a conference of past life regression therapists, featuring actress Shirley MacLaine's channeler as the keynote speaker. C.A. flew to Denver to attend. Akin to an 
anthropologist studying an exotic culture, she mingled with attendees, including people who had recovered "memories" from their previous lives as well as the therapists who practiced hypnotic past life regression therapy. At the conference banquet, C.A. met past lifers whose conversation often turned to their previous incarnations. One woman said that she was Anne Frank in a previous life, whereas a firefighter from a small New England town mentioned that he had previously been General Gordon, an officer of the Confederacy during the American Civil War. He gave C.A. a copy of his privately published book, a dual memoir of his past life and his current one. The cover featured photographs of General Gordon and himself. The resemblance was striking. Despite their unusual beliefs, the past lifers did not appear mentally ill, consistent with the scant literature on this topic (Pyun \& Kim, 2009; Spanos, Menary, Gabora, DuBreuil, \& Dewhirst, 1991).

Having "memories" of past lives is very unusual, even among adherents of Hinduism and Buddhism. Their mainstream doctrines endorse reincarnation, but deny that people can recover memories from previous lives unless they have attained extraordinary spiritual enlightenment as the Buddha reportedly did 
After returning to Cambridge, C.A. began recruiting past lifers via the Internet and past life regression therapists in the Boston area. She had no shortage of participants. Indeed, recruiting past lifers seems far easier than recruiting space alien abductees.

C.A. conducted in-depth, qualitative interviews with past lifers who contacted our laboratory. Popular lore has it that most people who have "memories" of their previous lives report having been especially important or famous (e.g., Anne Frank). Yet in our research, this was the exception, not the rule. For example, previous lives included a newspaper boy in 19th century Boston, an assistant to an Egyptian pharaoh, a Viking, a Druid priestess, Mark Twain's wife, a Native American brave, and a polar bear. One subject claimed to have been a space alien in a previous life.

For our first study (Meyersburg, Bogdan, Gallo, \& McNally, 2009), we administered a variant of the DRM paradigm to 15 past lifers (13 women) and 15 (13 women) comparison participants who reported having memories from only one life, their current one. The past lifers reported a mean number of 4.4 previous lives and the range ran from one to 20 past lives. They interpreted a diversity of phenomena as memories 
from previous lives including vivid dreams, déjà vu experiences, imagery surfacing during past life regression therapy, and "physical" memories.

The results indicated that past lifers exhibited significantly higher rates of false recall and false recognition than did comparison participants. As in our previous studies with women reporting recovered memories of sexual abuse (Clancy et al., 2000) and with space alien abductees (Clancy et al., 2002), past lifers did not differ from comparison participants in rates of correct recall and recognition. That is, participants who report recalling memories of CSA, abduction, or past lives do not have problems remembering words that did occur during the encoding phase. Rather, their difficulty arises when they "remember" critical lures that reflect the gist of the word list that did not appear during the encoding phase. Similar to alien abductees, past lifers score significantly higher on measures of absorption and magical ideation than do comparison participants. Unlike space alien abductees, whose experience with isolated sleep paralysis accompanied by hypnopompic hallucinations cry out for explanation, past lifers did not mention these episodes. 
Launching additional research, C.A. recruited 40 past lifers (30 women), including several who had participated in our DRM experiment, and 35 comparison participants (26 women) in an effort to elucidate the psychology of past lifers. The past lifers were similar to our previous group; their mean number of past lives was 5.35 and the number of past lives ranged from one to 22 .

Given their elevated levels of absorption and magical ideation (Meyersburg et al., 2009), we tested whether past lifers score higher than do comparison participants on a range of measures associated with creativity (Meyersburg, Carson, Mathis, \& McNally, 2011). Although scores on measures of schizotypy, such as magical ideation scales, are associated with psychosis proneness (Eckblad \& Chapman, 1983), they also predict creative achievement, at least in driven people with high intelligence (Carson, Peterson, \& Higgins, 2003). Scores on these scales also predict diminished latent inhibition on laboratory tasks (e.g., Baruch, Hemsley, \& Gray, 1988). Diminished latent inhibition also predicts creative achievement in people with high intelligence (Carson et al., 2003). Latent inhibition denotes the capacity to ignore irrelevant stimuli that do not predict significant events, rendering it difficult for people 
and animals subsequently to form associations between these stimuli and significant events when these stimuli come to predict them. For example, in Pavlovian conditioning, it is harder to establish a cue as a conditioned stimulus for an unconditioned stimulus if participants have already received nonreinforced preexposure to the cue relative to novel cues unfamiliar to the participants.

We administered a battery of questionnaires and a laboratory latent inhibition task to past lifers and to comparison participants, predicting that the past lifers would score higher on these measures than would our comparison participants.

Our results were consistent with this hypothesis. On the Creative Personality Scale (Gough, 1979), past lifers endorsed significantly more adjectives as self-descriptive that creative people endorse (e.g., inventive) and fewer adjectives that creative people do not endorse (e.g., conventional) relative to our comparison participants. Relative to comparison participants, past lifers scored higher on measures of divergent thinking (Torrance, 1968). That is, when we asked participants to think of alternative uses for an object, such as brick, the past lifers generated significantly more uses for the object, and these responses 
received ratings of greater originality than did the responses of the comparison participants.

To investigate latent inhibition, we used a computerized variant of Peterson and Carson's (2000) task, inspired by a previous version (Lubow, Ingberg-Sachs, Zalstein-Orda, \& Gewirtz, 1992). It consisted of a preexposure phase and an exposure phase. During the preexposure phase, participants heard a brief white noise (the target stimulus) that occurred randomly 31 times during an audio recording of a woman reading a series of 30 nonsense syllables repeated five times for a total of 150 presentations in a single uninterrupted stream. For this phase, we asked participants to count how many times they heard the nonsense syllable, "bim", during the audiotape. This syllable occurred five times. The volume of the white noise was about two-thirds as loud as that of the nonsense syllables.

During the exposure phase, participants again listened to this audiotape. However, this time, they also viewed a series of yellow circles that appeared one at a time on a computer screen as the audiotape was playing. The white noise began immediately prior to the appearance of a circle. The appearance of circles was unrelated to the occurrence of any of the nonsense syllables on the audiotape, and once a 
circle had appeared, it remained on the screen. The participants' task was to determine the stimulus that signaled the appearance of a circle, and to raise their hands once they believed that a circle was about to appear. After a subject had correctly raised his or her hand three times (i.e., when the white noise sounded), the experimenter paused the task, enabling the subject to state what stimulus predicts the occurrence of a circle. If the subject correctly claimed that onset of white noise predicted the appearance of a circle, then the task was over. On the other hand, if the subject's guess was incorrect, the task continued until the subject identified the rule or until all 31 circles had appeared on the computer screen. Relative to the comparison group (36\%), a significantly greater proportion of the past life group (59\%) correctly identified the white noise as the stimulus signaling the onset of circles. That is, preexposure to the noise produced less latent inhibition in the past lifer group than in the comparison group as evinced by the greater proportion of past lifers who grasped the rule relating white noise to the appearance of circles. However, the mean number of circles appearing prior to participants' identifying the rule was not significantly fewer in the past life group than in the 
comparison group (21 versus 23). Hence, the hypothesis that past lifers would exhibit lower latent inhibition relative to comparison participants received confirmation from the first analysis, but not the second one.

Finally, we administered the Creative Achievement Questionnaire (CAQ; Carson, Peterson, \& Higgins, 2005) to both groups, testing whether the past lifers had greater levels of documented creative achievement relative to the comparison group. The CAQ surveys 10 domains: visual arts; music; dance; architectural design; creative writing; humor; inventions; scientific discovery; theater and film; and culinary arts. A score of 12 or more in one of these domains signifies a high level of creative achievement (Carson et al., 2003). Relative to the comparison group $(M=13.3, S D=$ 12.7, range: $0-38)$, the past life group $(M=17.7, S D=$ 16.6, range: 0 - 74) tended to score higher on the CAQ, $p=$ .10. The distribution, however, for both groups was skewed with most participants at the lower end of creative achievement, and the marginally significantly higher average creative achievement in the past life group was attributable, in part to several extremely creative individuals. Both groups ranged widely in IQ scores (past life group: 98-136 
vs. comparison group: 90-142), but the means were both 120 . On average, both groups of participants were bright. Nonpsychotic people who report recalling memories from previous lives risk the stigma of mental illness. Accordingly, we tested hypotheses about possible countervailing benefits that past lifers may obtain, such as reduced distress about their own mortality and enhanced meaning in life (Meyersburg \& McNally, in press). Consistent with these hypotheses, past lifers scored lower than did comparison participants on the Reasons for Death Fear Scale (Abdel-Khalek, 2002), The Death Anxiety Scale (Templer, 1970), and The Death Depression Scale-Revised (Templer et al., 2002). Moreover, on the Meaning in Life Questionnaire (Steger, Frazier, Oishi, \& Kaler, 2006), past lifers scored significantly higher than the comparison participants did on the achieved meaning subscale, whereas the groups did not differ significantly on the searching for meaning subscale.

\section{Conclusions}

There are similarities and differences between people who report memories of alien abduction and past lives. Both groups score high on measures of absorption and magical ideation, suggesting vivid imaginal capabilities and an openness to unusual ideas. Both groups have salient 
experiences that motivate a quest to ascertain their meaning. Isolated sleep paralysis, accompanied by hypnopompic hallucinations, figures very prominently in the lives of space alien abductees. None, however, seem to accept this psychobiological explanation for these terrifying episodes. In contrast, sleep paralysis does not figure in the narratives of past lifers whose inferences about their previous lives arise from a much more diverse set of salient experiences (e.g., déjà vu). Both groups appear to be psychologically healthy despite their "false memories." Indeed, these memories give shape to their identities in very important ways.

For example, I asked abductees in our psychophysiology study whether, if they could do it all over all again, would they rather not have been abducted. Although they mentioned how terrifying it was when they first began to experience abduction, as our psychophysiological study documents, they eventually put it all into perspective. They said their encounters with aliens had deepened their spiritual awareness of the universe, making them glad that there were powerful beings out there that cared for us and for the fate of the earth. Some proudly mentioned their selection for hybrid 
breeding programs. Ninety percent said that on balance, they were glad to have been abducted.

Our data on past lifers likewise suggest a quasispiritual motivation for embracing this distinctive identity. They are content with their lives and nondistressed about their mortality. Although devout Christians anticipate eternal life in Heaven, their beliefs require faith. In contrast, our past lifers believe in reincarnation, and they have what they regard as personal evidence that death is not the end. Indeed, they have "memories" of their previous life.

In his essay, "Science as a Vocation," Max Weber (1919/1946) famously proclaimed that secular science produces "disenchantment of the world" (p. 155), robbing it of its mystery, magic, and meaning by expelling the gods. Our space alien abductees and our past lifers hope to re-enchant it.

\section{Future Directions}

Alien abduction narratives have inspired much theoretical speculation (For reviews, see Clancy, 2005; Holden \& French, 2002), but experimental research has been scarce. The ratio of theory to data has been very large. Indeed, other than ours, very few laboratory experiments on alien abductees (French, Santomauro, Hamilton, Fox, \& 
Thalbourne, 2008) and past lifers (Peters, Horselenberg, Jelicic, \& Merckelbach, 2007) have appeared. What new directions might researchers take? One possibility would be to induce memories of abduction in the laboratory via hypnosis as spanos et al. (1991) did for past lives. Participants who possess more ingredients of our recipe (e.g., high magical ideation, absorption) would theoretically be more likely than would other participants to generate imagery confusable with memories of abduction. Despite its theoretical appeal, this approach does run the risk of creating quasi-permanent false memories of potentially frightening experiences. In fact, several of our abductees had developed subthreshold PTSD after acquiring "memories" of abduction. The challenge would be to test our provisional theory in ethically unimpeachable ways.

In contrast to abductees, past lifers seem very heterogeneous. For example, only a minority has undergone hypnotic past life regression therapy, and these people likely differ from those whose memories arise from déjà vu episodes. Accordingly, researchers need to formulate "recipes" for past lifer subtypes as we have done for the alien abductees. 


\section{References}

Abdel-Khalek, A. (2002). Why do we fear death?: The construction and validation of the Reasons for Death Fear Scale. Death Studies, 26, 669-680.

Baruch, I., Hemsley, D. R., \& Gray, J. A. (1988). Latent inhibition and "psychotic proneness" in normal subjects. Personality and Individual Differences, 9, 777-783.

Beck, A. T., \& Steer, R. A. (1987). Beck Depression Inventory manual. San Antonio, TX: Psychological Corporation.

Bernstein, E. M., \& Putnam, F. W. (1986). Development, reliability, and validity of a dissociation scale. Journal of Nervous and Mental Disease, 174, 727-735. Carson, S. H., Peterson, J. B., \& Higgins, D. M. (2003). Decreased latent inhibitions associated with increased creative achievement in high-functioning individuals. Journal of Personality and Social Psychology, 85, $499-506$.

Carson, S. H., Peterson, J. B., \& Higgins, D. M. (2005). Reliability, validity, and factor structure of the creative achievement questionnaire. Creativity Research 
Journal, $17,37-50$.

Clancy, S. A. (2005). Abducted: How people come to believe they were kidnapped by aliens. Cambridge, MA: Harvard University Press.

Clancy, S. A., \& McNally, R. J. (2005/2006). Who needs Repression? Normal memory processes can explain "forgetting" of childhood sexual abuse. Scientific Review of Mental Health Practice, 4, 66-73.

Clancy, S. A., McNally, R. J., Schacter, D. L., Lenzenweger, M. F., \& Pitman, R. K. (2002). Memory distortion in people reporting abduction by aliens. Journal of Abnormal Psychology, 111, 455-461.

Clancy, S. A., Schacter, D. L., McNally, R. J., \& Pitman, R. K. (2000). False recognition in women reporting recovered memories of sexual abuse. Psychological Science, 11, 26-31.

Crews, F. (1995). The memory wars: Freud's legacy in dispute. New York: New York Review of Books. Deese, J. (1959). On the prediction of occurrence of particular verbal intrusions in immediate recall. Journal of Experimental Psychology, 58, 17-22. Eckblad, M., \& Chapman, L. J. (1983). Magical ideation as an indicator of schizotypy. Journal of Abnormal Psychology, 
$51,215-225$

French, C. C., Santomauro, J., Hamilton, V., Fox, R., \& Thalbourne, M. A. (2008). Psychological aspects of the alien contact experience. Cortex, 44, 1387-1395.

Gough, H. G. (1979). A creative personality scale for the adjective check list. Journal of Personality and Social Psychology, 37, 1398-1405.

Harman, G. (1965). The inference to the best explanation. Philosophical Review, 74, 88-95.

Hinton, D. E., Pich, V., Chhean, D., Pollack, M. H., \& McNally, R. J. (2005). Sleep paralysis among Cambodian refugees: Association with PTSD diagnosis and severity. Depression and Anxiety, 22, 47-51.

Hobson, J. A. (1995). Sleep. New York: Scientific American Library

Holden, K. J., \& French, C. C. (2002). Alien abduction experiences: Some clues from neuropsychology and neuropsychiatry. Cognitive Neuropsychiatry, 7, 163-178. Hufford, D. J. (1982). The terror that comes in the night: An experience-centered study of supernatural assault traditions. Philadelphia, PA: University of Pennsylvania Press. 
Keane, T. M., Kolb, L. C., Kaloupek, D. G., Orr, S. P., Blanchard, E. B., Thomas, R. G., Hsieh, F. Y., \& Lavori, P. W. (1998). Utility of psychophysiological measurement in the diagnosis of posttraumatic stress disorder: Results from a Department of Veterans Affairs Cooperative Study. Journal of Consulting and Clinical Psychology, 66, 914-923.

Lang, P. J., Levin, D. N., Miller, G. A., \& Kozak, M. J. (1983). Fear behavior, fear imagery, and the psychophysiology of emotion: The problem of affectiveresponse integration. Journal of Abnormal Psychology, $92,276-306$.

Lubow, R. E., Ingberg-Sachs, Y., Zalstein-Orda, N., \& Gewirtz, J. C. (1992). Latent inhibition in low and high "psychotic-prone" normal subjects. Personality and Individual Differences, 13, 563-572.

Mack, J. E. (1994). Abduction: Human encounters with aliens (rev. ed.). New York: Ballantine.

McNally, R. J. (2003) . Remembering trauma. Cambridge, MA:

The Belknap Press of Harvard University Press. McNally, R. J. (2004). The science and folklore of traumatic amnesia. Clinical Psychology: Science and Practice, 11, 29-33. 
McNally, R. J. (2007). Dispelling confusion about traumatic dissociative amnesia. Mayo Clinic Proceedings, 82, $1083-1087$

McNally, R. J. (in press). Searching for repressed memory. Nebraska Symposium on Motivation.

McNally, R. J., \& Clancy, S. A. (2005a). Sleep paralysis, sexual abuse, and space alien abduction. Transcultural Psychiatry, 42, 113-122.

McNally, R. J., \& Clancy, S. A. (2005b). Sleep paralysis in adults reporting repressed, recovered, or continuous memories of childhood sexual abuse. Journal of Anxiety Disorders, 19, 595-602.

McNally, R. J., Lasko, N. B., Clancy, S. A., Macklin, M. L., Pitman, R. K., \& Orr, S. P. (2004). Psychophysiological responding during script-driven imagery in people reporting abduction by space aliens. Psychological Science, 15, 493-497.

McNally, R. J., Luedke, D. L., Besyner, J. K., Peterson, R. A., Bohm, K., \& Lips, O. J. (1987). Sensitivity to stress-relevant stimuli in posttraumatic stress disorder. Journal of Anxiety Disorders, 1, 105-116. Meyersburg, C. A., Bogdan, R., Gallo, D. A., \& McNally, R. J. (2009). False memory propensity in people reporting 
recovered memories of past lives. Journal of Abnormal Psychology, 118, 399-404.

Meyersburg, C. A., Carson, S. H., Mathis, M. B., \& McNally,

R. J. (2011). Creativity, latent inhibition, and

personality boundaries in people reporting past life

memories. Manuscript in preparation.

Meyersburg, C. A., \& McNally, R. J. (in press). Reduced death

distress and greater meaning in life among individuals

reporting past life memory. Personality and Individual

Differences.

Orr, S. P., Metzger, L. J., \& Pitman, R. K. (2002).

Psychophysiology of post-traumatic stress disorder.

Psychiatric Clinics of North America, 25, 271-293.

Perina, K. (2004). Cracking the Harvard X-Files. In D. Sobel

(Ed.), The best American science writing 2004, (pp. 115-123). New York: Ecco.

Peters, M. J. V., Horselenberg, R., Jelicic, M., \& Merckelbach, H. (2007). The false fame illusion in people with memories about a previous life. Consciousness and Cognition, 16, 162-169.

Peterson, J. B., \& Carson, S. H. (2000). Latent inhibition and openness to experience in a high-achieving student 
population. Personality and Individual Differences, 28, $323-332$.

Piper, A. Jr., Pope, H. G., Jr., \& Borowiecki, J. J., III. (2000). Custer's last stand: Brown, Scheflin, and Whitfield's latest attempt to salvage "dissociative amnesia." Journal of Psychiatry and Law, 28, 149-213. Pyun, Y. D. \& Kim, Y.J. (2009). Experimental production of past-life memories in hypnosis. International Journal of Clinical and Experimental Hypnosis, 57, 269-278.

Roediger, H. L., III, \& McDermott, K. B. (1995). Creating false memories: Remembering words not presented in lists. Journal of Experimental Psychology: Learning, Memory, and Cognition, 21, 803-814.

Shin, L. M., Kosslyn, S. M., McNally, R. J., Alpert, N. M., Thompson, W. L., Rauch, S. L., Macklin, M. L., \& Pitman, R. K. (1997). Visual imagery and perception in posttraumatic stress disorder: A positron emission tomographic investigation. Archives of General Psychiatry, 54, 233-241.

Shin, L. M., McNally, R. J., Kosslyn, S. M., Thompson, W. L., Rauch, S. L., Alpert, N. M., Metzger, L. J., Lasko, N. B., Orr, S. P., \& Pitman, R. K. (1999). Regional cerebral blood flow during script-driven imagery in 
childhood sexual abuse-related PTSD: A PET investigation. American Journal of Psychiatry, 156, $575-584$.

Spanos, N. P., Menary, E., Gabora, N. J., DuBreuil, S. C., \& Dewhirst, B. (1991). Secondary identity enactments during hypnotic past-life regression: A sociocognitive perspective. Journal of Personality and Social Psychology, 61, 308-320.

Spielberger, C. D., Gorsuch, R. L., Lushene, R., Vagg, P. R., \& Jacobs, G. A. (1983). Manual for the State-Trait Anxiety Inventory. Palo Alto, CA: Consulting Psychologists Press.

Steger, M. F., Frazier, P., Oishi, S., \& Kaler, M. (2006). The Meaning in Life Questionnaire: Assessing presence of and search for meaning in life. Journal of Counseling Psychology, 53, 80-93.

Tellegen, A., \& Atkinson, G. (1974). Openness to absorbing and self-altering experiences ("absorption"), a trait related to hypnotic susceptibility. Journal of Abnormal Psychology, 83, 268-277.

Templer, D. I. (1970). The construction and validation of a death anxiety scale. The Journal of General Psychology, $82,165-177$. 
Templer, D. I., Harville, M., Hutton, S., Underwood, R., Tomeo, M., Russell, M., Mitroff, D., \& Arikawa, H. (2002). Death depression scale-revised. Omega: Journal of Death and Dying, 44, 105-112.

Torrance, E. P. (1968). Examples and rationales of test tasks for assessing creative abilities. Journal of Creative Behavior, 2, 165-178.

Weber, M. (1946). Science as a vocation. In H. H. Gerth \& C. W. Mills (Eds. \& Trans.), From Max Weber: Essays in sociology (pp. 129-156). New York: Oxford University Press. (Original work published 1919).

\section{Author Notes}

This article is based on an invited address delivered at the World Congress of Behavioral and Cognitive Therapies in Boston, Massachusetts, June 4, 2010 .

In this article, I quote conversational remarks from memory. Hence, they capture the gist of what was said, but not necessarily the verbatim words.

Our research on memories of alien abduction and past lives was supported by grants from the Clark Fund and the Stimson Fund. 
Correspondence should be sent to Richard J. McNally, Department of Psychology, Harvard University, 1230 William James Hall, 33 Kirkland Street, Cambridge, MA 02138 USA. Email: rjm@wjh.harvard.edu 